\title{
Submucous cleft palate in the differential diagnosis of feeding difficulties
}

\author{
A L H Moss, $\mathrm{K}$ Jones, $\mathrm{R}$ W Pigott
}

\begin{abstract}
Submucous cleft palate is a missed or forgotten diagnosis. We reviewed 81 patients with submucous cleft palate seen over a 15 year period; 26 of these patients were interviewed. The patients were divided into three main groups according to the referral pattern. Children under 2.5 years were referred by a paediatrician for feeding problems; children aged 2.5-10 were referred mainly by speech therapists; and those over 10 had a varied pattern of referral. Thirty nine of the 81 had problems with feeding, but of the 26 interviewed, 22 had feeding problems.

Not all patients with a submucous cleft palate are symptomatic and require active treatment, but children with this condition have the same high incidence of middle ear disease as those with overt cleft palate. We suggest that the diagnosis of submucous cleft palate be included in the differential diagnosis of feeding difficulties, with early referral to a specialist cleft palate team.
\end{abstract}

Submucous cleft palate is a forgotten or missed diagnosis and can be defined as the abnormal attachments of the palatal muscles with intact oral and nasal mucosa. ${ }^{12}$ This can therefore result not only in feeding and speech difficulties but also eustachian tube dysfunction with middle ear disease. ${ }^{3}$

The incidence of the condition is said to be one in $1200,{ }^{3}$ with a $4 \%$ incidence in a cleft lip and palate clinic population. ${ }^{4}$

The diagnosis of submucous cleft palate can be made on the classical triad of signs: that is, a bifid uvula, a translucent zone in the midline of the soft palate, and an absent or notched posterior nasal spine. These signs are not always evident, however, ${ }^{15}$ but must still be looked for. An isolated bifid uvula can occur in $0 \cdot 1-3 \%$ of the normal population. ${ }^{2}$ If the diagnosis is suspected the most reliable means of confirming it is barium coated videofluoroscopy and nasopharyngoscopy, where practical. ${ }^{12}$ This will confirm the loss of the normal musculus uvulae ridge on the nasal surface with the resulting valley in the midline, as also seen in the poorly repaired overt cleft palate patient. Should there be any indication for surgery, the muscles of the palate can be explored, the abnormal attachments confirmed, and then reconstructed in their normal position to create the levator sling.

Only $10 \%$ of cases of submucous cleft palate are symptomatic, ${ }^{3}$ but it is important that these patients are diagnosed to allow full assessment of middle ear function and speech as early treatment, if required, achieves the best results. ${ }^{6}$ The incidence of middle ear disease (recurrent infective otitis media or chronic secretory otitis media, or both) is as high as in the overt cleft palate, that is between $59-93 \% .^{2}$ In view of this the indications for adenoidectomy for repeated middle ear symptoms in these patients must be questioned as the cause of these symptoms may be due to the abnormal muscle attachments, and adenoidectomy may not improve the incidence of middle ear disease. Adenoidectomy may make a borderline velopharyngeal sufficiency into appreciable insufficiency requiring investigations and possible surgery. ${ }^{7} 8$ Another reason for avoiding adenoidectomy generally is that even with a normally functioning palate the pharynx may be relatively large (velopharyngeal disproportion), and nasal escape may result. ${ }^{9} 10$

\section{Patients and methods}

A review of the history, signs, symptoms, and referral patterns of patients with the diagnosis of submucous cleft palate first seen between 1972-87 was undertaken. The notes and video recordings were reviewed, and in addition, as many patients and parents as could attend were interviewed by a speech therapist and reconstructive plastic surgeon.

The patients were divided into age groups as follows: $0-2.5$ years $(2.5$ years tends to be the earliest an experienced speech therapist can assess speech), 2.5-5 years ( 5 years of age is when many children start school and any difficulties in the production of speech sounds are established), 5-10 years, 10-15 years, 15-20 years, and over 20 years. For clarity and simplifications of the tables, the groups have been amalgamated according to their referral pattern.

\section{Results}

The details of 81 patients with a proved submucous cleft palate were reviewed, although only 26 patients were available to be interviewed. There appeared to be three patterns of referrals (table 1 ) with those under 2.5 years (in fact under 18 months) being referred by a paediatrician with feeding problems (longer than 40 minutes to feed and nasal regurgitation). The feeding improved with surgery but seven out of nine children subsequently developed middle ear symptoms. This may reflect the natural history of chronic secretory otitis media in the normal population.

The second group were the children between $2 \cdot 5-10$ years where 46 out of 56 were referred 
Table 1 Referral pattern of patients with a submucous cleft palate to a cleft lip and palate clinic

\begin{tabular}{|c|c|c|c|c|c|c|c|c|c|c|}
\hline $\begin{array}{l}\text { Age group } \\
\text { (years) }\end{array}$ & $\begin{array}{l}\text { Speech } \\
\text { therapist }\end{array}$ & $\begin{array}{l}\text { Ear, nose, } \\
\text { and throat } \\
\text { surgeon }\end{array}$ & Paediatrician & $\begin{array}{l}\text { General } \\
\text { practitioner }\end{array}$ & $\begin{array}{l}\text { Oral } \\
\text { surgeon }\end{array}$ & Orthodontist & $\begin{array}{l}\text { School } \\
\text { medical } \\
\text { officer }\end{array}$ & Psychiatrist & Unknown & $\begin{array}{l}\text { Total } \\
\text { patients }\end{array}$ \\
\hline $\begin{array}{l}<2 \cdot 5 \\
2 \cdot 5-10 \\
>10\end{array}$ & $\begin{array}{r}29 \\
3\end{array}$ & $\begin{array}{r}17 \\
5\end{array}$ & $\begin{array}{l}9 \\
3\end{array}$ & $\begin{array}{l}3 \\
2\end{array}$ & 3 & $\begin{array}{l}1 \\
1\end{array}$ & $\begin{array}{l}1 \\
1\end{array}$ & 1 & 2 & $\begin{array}{r}9 \\
56 \\
16\end{array}$ \\
\hline Total patie & 32 & 22 & 12 & 5 & 3 & 2 & 2 & 1 & 2 & 81 \\
\hline
\end{tabular}

Table 2 Incidence of the main symptoms associated with submucous cleft palate in the three groups

\begin{tabular}{llccc}
\hline $\begin{array}{l}\text { Age group } \\
\text { (years) }\end{array}$ & \multicolumn{3}{l}{ Problems with: } & Total \\
\cline { 2 - 4 } & Speech & Ears & Feeding & \\
\hline$<2 \cdot 5$ & $\overline{5}$ & 7 & 9 & 9 \\
$2 \cdot 5-10$ & 56 & 40 & 23 & 56 \\
$>10$ & 16 & 5 & 7 & 16 \\
\hline Total & 72 & 52 & 39 & 81 \\
\hline
\end{tabular}

by speech therapists or ear, nose, and throat specialists for speech difficulties; 40 of this group had middle ear pathology (table 2). Twenty three of these 56 children had a positive history of feeding difficulties as a baby; the incidence may be a higher as this aspect is not always documented.

The last group were over 10 years of age where there was a diffuse pattern of referral, although all had speech problems. Seven out of 16 had a history of feeding difficulties as a baby but again the incidence may be higher.

Of the 26 patients and parents interviewed, 22 gave a positive history of slowness to feed and nasal regurgitation; the other four could not remember.

\section{Discussion}

There is very little written, even in standard textbooks, about normal variables of feeding in neonates, although the physiology of suck and swallowing is well documented. ${ }^{11-15}$ Feeding should take five to 20 minutes with half in the first two minutes and $80-90 \%$ completed by four minutes. ${ }^{15} \mathrm{~A}$ more recent study has shown a wider range of feeding times for normal breast fed babies (four to 23 minutes) with an average of $54-58 \%$ of the intake achieved by four minutes. ${ }^{17}$ The more common yardstick as to normal feeding is the baby's ability to maintain and increase his weight, however long it takes. ${ }^{18}$ This is not always practical, however, as $13 \%$ of mothers give up breast feeding in the first two weeks because 'feeding takes too long and is too tiring'. ${ }^{19}$ Others have defined slowness to feed as taking longer than 30 minutes. ${ }^{13}$ We have defined 'slowness to feed' as taking longer than 40 minutes.

Little is mentioned of 'feeding difficulties' in the normal population. There are many causes of 'slowness to feed', however, including respiratory, cardiovascular, renal, infective, neurogenic, and myopathic. ${ }^{11-1418}$ Cleft lip or overt cleft palate, or both, are well known causes of problems with feeding but 'Cleft palates may be small and submucous or extensive and associated with considerable nasal regurgitation and choking during feeds"11 or 'rarely cause problems, but in severe defects sucking and swallowing may be difficult'. ${ }^{13}$ There is even less written about 'nasal regurgitation', which should be defined as the emission of fluid out of the nose during peaceful feeding (to differentiate from vomiting). The only causes of this are overt clefting of the palate or neuromuscular incoordination of the velopharynx (for example, suprabulbar palsy). ${ }^{11} 1218$ There appears to be no mention of submucous cleft palate as a cause of this symptom. As nasal regurgitation is a form of velopharyngeal insufficiency, ${ }^{14}$ which is usually associated with speech abnormalities, it is not surprising that feeding problems are directly related to subsequent difficulties in speech development. ${ }^{20}$ Therefore the combination of slowness to feed and nasal regurgitation in the neonate or baby should alert the midwife, health visitor, obstetrician, and neonatologist to the possibility of a submucous cleft palate being present.

The examination of the neonate is not always explicit in advocating palpation of the roof of the mouth with the tip of the little finger, but suggests that 'the soft and hard palate should be inspected for a hidden cleft'. ${ }^{21}$ Absence or notching of the posterior nasal spine is the most commonly present of the three classical signs, ${ }^{145}$, although the absence of signs should not prevent the diagnosis of submucous cleft palate being considered. If the condition is suspected, an early referral to a cleft lip and palate clinic is indicated.

It is unfortunate that more paediatricans are not regularly involved in cleft lip and palate clinics as more research into feeding, speech, and eustachian tube function would result in better understanding of these complex mechanisms and allow us to tailor the treatment to the specific anatomical and physiological problem. ${ }^{129} 1022$

In conclusion it is suggested that the combination of a 'slowness to feed' ( $>40$ minutes) and 'nasal regurgitation' (velopharyngeal insufficiency) is strongly suggestive of a submucous cleft palate, assuming there is no other obvious cause of these symptoms. It is also suggested that those babies with feeding difficulties as a result of a submucous cleft palate will stand a high chance of developing middle ear disease as well as significant nasal escape and should therefore be kept under regular review by a 'cleft palate team'. Adenoidectomy should be avoided in this group even if the patients appear to have acceptable speech as speech could deteriorate after the procedure. 
1 Moss ALH, Jones K, Pigott RW. Submucous cleft palate. $\mathrm{Br}$ Med J 1988;297:85-6.

2 Shprintzen RJ, Schwartz RH, Daniller A, Hoch L. Morphologic significance of bifid uvula. Pediatrics 1975;75:553-61. Weatherley-White RCA, Sakura CY, Brenner LD, Stewart JM, Ott JE. Submucous cleft palate. Plast Reconstruct Surg $1972 ; 49: 297-304$

4 Crikelair GF, Striker P, Cosman B. The surgical treatment of submucous cleft palate. Plast Reconstruct Surg 1970;45: 58-65.

5 Trier WC. Velopharyngeal incompetency in the absence of overt cleft palate; anatomic and surgical considerations. Cleft Palate $\mathcal{F}$ 1983;20:209-17.

6 Porterfield HW, Trabue JC. Submucous cleft palate. Plast Reconstruct Surg 1965;35:45-50.

7 Croft CB, Shprintzen RJ, Ruben RJ. Hypernasal speech following adenotonsillectomy. Otolaryngol Head Neck Surg 1981;89:179-88.

8 Witzel MA, Rich RH, Margar-Bacal F, Cox C. Velopharyngeal insufficiency after adenoidectomy: an 8 year review. Int $\mathcal{F}$ Pediatr Otorhinolaryngol 1986;11:15-20.

9 Moss ALH, Pigott RW, Albery EH. Hynes pharyngoplasty revisited. Plast Reconstruct Surg 1987;79:346-53.

10 Pigott RW. Objectives for cleft palate repair. Ann Plast Surg 1987;19:247-59.

11 Gryboski J. Suck and swallow. Gastrointestinal problems in the infant. Philadelphia: WB Saunders, 1975:17-47.

12 Fisher SE, Painter M, Milmoe G. Swallowing disorders in infancy. Pediatr Clin North Am 1981;28:845-53.
13 Gandy GM, Roberton NRC. Lecture notes on neonatology. Oxford: Blackwell Scientific Publications, 1987.

14 Kilman WJ, Goyal RK. Disorders of pharyngeal and upper esophageal sphincter motor function. Arch Intern Med 1976;136:592-601

15 Barness LA. Feeding of infants. In: Behrman RE, Vaughan VC, eds. Nelson textbook of pediatrics. Philadelphia: WB Saunders, 1983:148-65.

16 Lucas A, Lucas PJ, Baum JD. Pattern of milk flow in breastfed infants. Lancet 1979;ii:57-8.

17 Woolridge MW, Baum JD, Drewett RF. Individual patterns of milk intake during breast-feeding. Early Hum Dev 1982;7:265-72.

18 Barbero GJ, McKay RJ. Failure to thrive. In: Behrman RE Vaughan VC, eds. Nelson textbook of pediatrics. PhiladelVaughan VC, eds. Nelson textboo
phia: WB Saunders, 1983:253-4.

19 Martin J, White A. Infant feeding 1985. London: HMSO, 1988.

20 Miller CJ. Children with feeding problems. Child Care Health Dev 1976;2:73-6.

21 Behrman RE, Kliegman RM. The newborn infant. In: Behrman RE, Vaughan VC, eds. Nelson textbook of pediat rics. Philadelphia: WB Saunders, 1983:331-8.

22 Paradise JL, Alberti PWRM, Bluestone CD, Cheek DB, Lis EF, Stool SE. Pediatric and otologic aspects of clinical research in cleft palate. Clin Pediatr (Phila) 1974;13: 587-93 